\title{
Building Strong Customer Relationships through Brand Orientation in Small Service Firms: An Empirical Investigation
}

\section{Miloslava Chovancová}

Tomas Bata University in Zlin, Faculty of Management and Economics, Czech Republic

chovancova@fame.utb.cz

\section{Christian Nedu Osakwe}

Tomas Bata University in Zlin, Faculty of Management and Economics, Czech Republic

osakwe@fame.utb.cz

\section{Benson U. Ogbonna}

University of Port Harcourt, Department of Marketing, Nigeria benson.ogbonna@uniport.edu.ng

\author{
CroEconSur \\ Vol. 17 \\ No. 1 \\ June 2015 \\ pp. $111-138$
}

Received: February 23, 2015

Accepted: May 28, 2015

Research Article

doi:10.15179/ces.17.1.4

\section{Abstract}

The purpose of this paper is to empirically examine the relationship between the adoption of a brand orientation strategy and customer relationship performance in a small service firm setting. More specifically, in addition to investigating the direct link between brand orientation and customer relationship performance, we further examine the moderating effects of entrepreneurial orientation and perceived competitive intensity on the empirical link between brand orientation and customer relationship performance. To test the hypothesized relationships in the conceptual framework, 105 usable structured questionnaires were collected from small service firms and the data were further analyzed using a hierarchical, moderated regression analysis. The results affirm the positive link between brand orientation and customer relationship performance. Moreover, entrepreneurial orientation is found to strengthen the brand orientation-customer relationship 
performance link. However, our results show that competitive intensity does not significantly moderate the brand orientation-customer relationship performance link. Nonetheless, it is highly suggestive that perceived competitive intensity is a direct predictor of customer relationship performance. In terms of the practical significance of the overall research model, the effect size is fairly large (Cohen's $\left.f^{2}=0.33\right)$. The research implications and directions for future research are further highlighted in the penultimate section of the paper.

Keywords: brand orientation, customer relationship performance, entrepreneurial orientation, perceived competitive intensity, small service firm

JEL classification: G20, L20, M13, M31

\section{Introduction}

Small firms in general make significant contributions to the advancement of the global economy in terms of job creation, entrepreneurship, innovation, wealth creation, and nation building (Džafić et al., 2011; International Labour Organization, 2006; Mead and Liedholm, 1998). Consequently, there has been a growing interest among academics in the study of small businesses across the broader spectrum of the social sciences discipline. Further, as a result of increasing competition in the business environment, marketing scholars (Abimbola and Vallaster, 2007; Berthon, Ewing and Napoli, 2008; Wong and Merrilees, 2005) have even suggested that the adoption of a brand(ing) strategy is vital for the growth of these enterprises as well as their competitiveness in the marketplace, particularly those in the service sector. In fact, a recent study empirically demonstrates that small and medium-sized firms "are at a competitive disadvantage, on account of weaker brand orientation than in larger companies" (Baumgarth, 2010: 666). This may imply that small service firms that are brand-oriented stand a better chance of using their brand to establish "stronger" symbiotic brand-customer relationships in a rapidly changing and competitive 
marketplace. Accordingly, a firm's brand orientation is more likely to serve as a strategic leeway for survival in intensely competitive business environments (Urde, 1994).

However, for small firms, the role of the business entrepreneur cannot be underscored regarding the formulation and/or implementation of a brandoriented culture within the firm (Napoli, Ewing and Berthon, 2005; Wong and Merrilees, 2005). Therefore, it is expected that a small firm's brand orientation in connection with its brand performance outcomes, in this instance, customer relationship performance, is more likely to be contingent on the entrepreneurial orientation of the firm as well as the level of competition in the firm's business environment.

On the other hand, there is scant literature on how branding supposedly influences customer relationship performance of micro, small and medium-sized companies, particularly in the case of small service firms (Laukkanen et al., 2013; Merrilees, Rundle-Thiele and Lye, 2011). To address the gap in scholarly literature, our goal is to empirically investigate in this research paper whether the adoption of a brand orientation, as a marketing strategy, could significantly predict the customer relationship performance of small service firms. In addition, we further examine whether or not a firm's entrepreneurial orientation, together with perceived competitive intensity, moderates the relationship between brand orientation and customer relationship performance in a small service firm setting.

In sum, this paper makes at least three contributions to the scholarly business literature. First, we further extend and establish that there is a direct link between brand orientation and customer relationship performance in the context of small service firms. Second, to the extent of our knowledge, this study is arguably the first to incorporate the moderating effects of entrepreneurial orientation and perceived competitive intensity in the brand orientation-customer relationship performance linkage. In fact, this is obviously a response to the call by Baumgarth (2010: 666) for additional strategic variables to be incorporated into 
a single research framework comprising brand orientation and organizational performance, as measured in this case by customer relationship performance. Finally, this study demonstrates that brand orientation is also relevant for small service firms operating in less-developed market economies, thus extending the generalizability of brand orientation beyond the very few empirical findings in mature market economies (cf. Laukkanen et al., 2013).

The research paper is further arranged as follows. The next section presents the conceptual framework of the study, relevant theoretical background and research hypotheses. In the subsequent section, we describe the research methodology, including the measures that were used for the survey, as well as the software that aided our statistical analysis. Empirical findings and discussion are highlighted in the section after that, while the research implications, including limitations and future study are presented in the penultimate section of the article. The final section briefly presents the concluding thoughts.

\section{Conceptual Framework, Theoretical Foundations and Hypotheses}

The conceptual framework of the study is as illustrated in Figure 1.

Figure 1: The Conceptual Framework

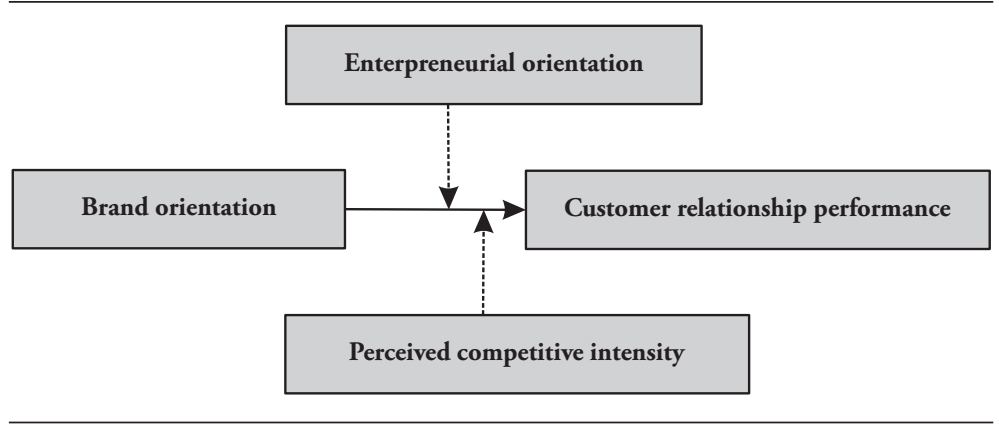

Note: The horizontal undotted arrow represents the direct effect, while the dotted arrows indicate moderating effect. Source: Authors. 


\subsection{Brand Orientation and Customer Relationship Performance}

As adduced by Van Gelder (2003), brands are constructs which are created by organizations to stimulate customer experience and with the hope of inducing a buying behavior that is both favorable and sustainable to firms. Accordingly, a brand that is well-crafted tends to appeal more to consumers, and in turn tends to be more visible in the marketplace, thereby leading to satisfactory marketing performance outcomes (e.g., customer relationship performance) (Aaker, 1996a; Kapferer, 2008). Undoubtedly, brand orientation is a tortuous marketing strategy since it requires a web of interrelated mechanisms and linkages that represent both the "face" and "voice" of the organization in the marketplace (Napoli, Ewing and Berthon, 2005; Urde, 1994; Urde, Baumgarth and Merrilees, 2013; Wong and Merrilees, 2005). In one of the thought-provoking literary discourses on the synergy between brand orientation and market orientation, Urde (1999: 118) unequivocally states that "to be brand oriented is market orientation 'plus'". Similarly, some recent empirical studies posit that brand orientation fosters the brand performance of not only large corporations, but also small and mediumsized businesses (Baumgarth, 2010; Merrilees, Rundle-Thiele and Lye, 2011; Park and Kim, 2013). Additionally, the study of O'Cass and Ngo (2011) provides further empirical proof that the brand orientation (or branding capability as the authors would prefer to call it) of a service-oriented firm positively relates to customer empowerment as well as customer satisfaction. Although not much empirical research has been done in this area, especially in the context of small service firms, we align our thoughts to some of the aforementioned studies and further propose that:

H1: Brand orientation positively relates to a firm's customer relationship performance. 


\subsection{Brand Orientation, Its Interaction with Entrepreneurial Orientation, and Customer Relationship Performance}

Berthon, Ewing and Napoli (2008) argue that a firm's brand orientation is likely to be more impactful on the organizational performance of SMEs with a penchant for creativity and foresight, as well as those that possess an uncanny knack of identifying new business opportunities. This is also consistent with the views of Schmidt and Baumgarth (2014) who stress in their paper the need for social entrepreneurs to scale up their innovative efforts towards building their brand identity so that they could attract more positive outcomes from various stakeholders in the society. More specifically, we would expect that small service firms that are more enterprising, proactive, innovative and, importantly, have a clear-cut mission with a long-term strategic vision for their businesses, are more likely to build a long-lasting brand with a unique identity that is "tied" to their internalized brand values (Hankinson, 2002; Lumpkin and Dess, 2001; Urde, 1999; Wallace, de Chernatony and Buil, 2011). As such, enterprises with more forward-looking and innovative entrepreneurs are bound to be more creative with their product and/or service offering in the marketplace so that they could possibly forge a good relationship with their customers via their firms' brands. Accordingly, entrepreneurial orientation could serve as a buffer for small service firms that are interested in using their brand identity to influence consumers' perceptions of their brand, thereby strengthening the firm's bonding and/ or relationships with its customers. Thus, the interaction of brand orientation with entrepreneurial orientation is more than likely to significantly influence the customer relationship performance of a small service firm. Against this background, we further propose that:

H2: The relationship between a firm's brand orientation and customer relationship performance is reinforced under high entrepreneurial orientation. 


\subsection{Brand Orientation, Its Interaction with Perceived Competitive Intensity, and Customer Relationship Performance}

The whole essence of branding is differentiation, when a firm is able to distinguish itself from rival firms via the branding strategy that it decides to adopt and/ or implement in the marketplace. Accordingly, brand orientation is a strategic resource which enables a firm to compete in the marketplace (Urde, 1994); it could also be seen in the light of "marketing orientation plus" (Urde, 1999). In fact, existing literature has shown that a firm's branding strategy strongly correlates with its customer-based brand equity outcomes, such as brand awareness, brand association, perceived service quality, brand trust, and brand satisfaction/loyalty (Aaker, 1996a; 1996b). The above may equally imply that what drives firms to implement an effective branding strategy in the marketplace stems from the level of competition in the business environment. Besides, scholarly literature asserts that branding plays a vital role in achieving superior customer value, particularly in an intensely competitive business environment (Abimbola and Vallaster, 2007; Kapferer, 2008; Urde, 1999). It suffices to say that a competitive business environment provides the external impetus for firms to mobilize and invest their scarce resources in the implementation of effective branding strategies. Branding strategy, or more specifically, a firm's brand orientation enables the firm to leverage on its brand name with a view to strengthen the firm's relationship with its stakeholders, especially existing and potential customers. However, to date, no previous research has empirically demonstrated the interaction of brand orientation with perceived competitive intensity and the likely impact it might have on the measure of customer relationship performance in a small firm setting. On the other hand, existing literature proposes that the dominant rationale behind the brand orientation of firms could be attributable to the degree of competition that exists in the business environment. This evinces that a brand-oriented firm is more likely to be influenced based on its perception of competitive intensity in its industry, which in turn is likely to amplify the brand orientation-customer relationship performance link. In fact, as O'Cass and Weerawardena (2010) 
demonstrate in their empirical study, perceived industry competitive intensity has a positive, indirect effect on a firm's brand performance metric (i.e., brandcustomer loyalty) via the firm's choice of marketing capabilities (e.g., promotion of the firm's brand and product differentiation). Thus, drawing from previous research we would expect that a highly-competitive business environment, albeit based on a service firm's perception, is more likely to trigger business creativity among the service firms and in turn strengthens the brand orientation-customer relationship performance of these firms. This leads us to the following research hypothesis:

H3: The relationship between a firm's brand orientation and customer relationship performance is reinforced under a higher perception of competitive intensity.

\section{Research Methodology}

\subsection{Data Collection and Sample}

The setting for the research is Nigeria, which is one of the world's fastest growing market economies, yet a developing country with myriads of institutional, infrastructure and business challenges facing the growth of micro, small and medium-sized companies in general. The units of analysis are small service firms. Through the use of a quota sampling method, survey data were gathered from selected service firms such as micro finance banks (MFBs), insurance brokers, and finance houses. Thus, having selected the types of firms that we wanted to include as members of the target population, firms were further picked in a non-randomized manner (i.e., non-random selection). Accordingly, structured questionnaires were used to elicit responses from the target population. The data were often collected by means of a drop and pick method in order to overcome the challenge of an inefficient postal delivery system, as this is often the case with less advanced economies. Also, in rare cases, the questionnaires were emailed to some of the key respondents that had indicated interest to participate in the survey. Data collection took place in the southern part of Nigeria, including the 
nation's seat of political power (i.e., Abuja). One of the researchers that was on the ground and several trained research assistants were able to administer 170 questionnaires to the survey respondents. A total number of 105 questionnaires were returned at the time of writing this article. Thus, the 105 completed questionnaires were deemed to be appropriate for the study. The participants in the study included CEOs and managers of the firms. Data collection was from the month of November, 2014 to December, 2014. We had both male and female participants, though a larger proportion were males. Nearly all the firms covered in our study had between 10 and 49 employees with an insignificant proportion employing 50 to 249 employees (see Table 1). A breakdown of the sample characteristics is depicted in Table 1. More importantly, the sample size exceeds the criterion suggested by Green (1991) as well as Wilson VanVoorhis and Morgan (2007) for the intended statistical method that was used for the data analysis, that is, a hierarchical moderated regression analysis.

Table 1: Sample Characteristics

\begin{tabular}{l|c}
\hline Variable & Total (\%) \\
\hline Respondent's gender: & 19.1 \\
\hline Female & 80.9 \\
\hline Male & \\
\hline Respondent's educational qualification: & - \\
\hline Primary/secondary school education & 100 \\
\hline University education & \\
\hline Firm's size (number of employees): & 87.6 \\
\hline $10-49$ & 12.4 \\
\hline $50-249$ & \\
\hline Business type: & 59.8 \\
\hline Micro finance bank (MFB) & 35.4 \\
\hline Finance house & 4.8 \\
\hline Insurance brokerage &
\end{tabular}

Source: Authors' calculations. 


\subsection{Survey Instrument}

We adapted all our research constructs from the existing literature (e.g., Wong and Merrilees, 2008; Wu, Mahajan and Balasubramanian, 2003). All the constructs were measured on a multi-item scale ranging from strongly disagree (1) to strongly agree (5). The scale for brand orientation consisted of four items; the items were obtained from Wong and Merrilees (2008). The entrepreneurial orientation scale consisted of five items obtained from Laukkanen et al. (2013) while the measure of customer relationship performance was adapted from Wu, Mahajan and Balasubramanian (2003). The items measuring competitive intensity were obtained from Arnold, Fang and Palmatier (2011). The mean and standard deviation of the four research constructs are as shown in Table 2. In addition, the correlation matrix of the research constructs is presented in Table 3 .

Table 2: Mean and Standard Deviation of Research Constructs

\begin{tabular}{c|c|c}
\hline Construct & Mean & Std. Deviation \\
\hline CUPF & 2.581 & .718 \\
\hline BO & 2.495 & .680 \\
\hline EO & 2.851 & 1.081 \\
\hline PCI & 2.591 & .799 \\
\hline
\end{tabular}

Source: Authors' computations extracted from SPSS.

Table 3: Pearson Correlation Matrix of Research Constructs

\begin{tabular}{|c|c|c|c|c|}
\hline & BO & EO & CUPF & PCI \\
\hline $\mathrm{BO}$ & 1 & -.037 & $.337^{* * *}$ & $.173^{*}$ \\
\hline $\mathrm{EO}$ & -.037 & 1 & $.264^{* * *}$ & $.226^{* *}$ \\
\hline CUPF & $.337^{* * *}$ & $.264^{* * *}$ & 1 & $.288^{* * *}$ \\
\hline PCI & $.173^{*}$ & $.226^{* *}$ & $.288^{* * *}$ & 1 \\
\hline
\end{tabular}

Note: ${ }^{* * *} \mathrm{p}<0.01,{ }^{* *} \mathrm{p}<0.05,{ }^{*} \mathrm{P}<0.1$ (two-tailed test).

Source: Authors' computations extracted from SPSS. 


\subsection{Statistical Method and Software}

The data were analyzed using descriptive and inferential statistics. That is, in addition to descriptive statistics, we conducted exploratory factor analysis in order to check the unidimensionality of the research constructs. To test our hypotheses, we conducted a hierarchical, moderated regression analysis. For further elaboration on moderated regression analysis, please refer to related studies (Bergkvist, 2004; Sharma, Durand and Gur-arie, 1981). The data were warehoused in SPSS, thus, all our statistical analyses were done using IBM SPSS Statistics 19. We equally made use of a regression interaction software, Interaction 1.7.2211 (Soper, 2012).

\section{Results, Empirical Findings and Discussion}

\subsection{Common Method Bias and Psychometric Properties of Scale}

By default, our analysis is likely to suffer from a common method bias (CMB) given that we collected our data including the outcome variable from a single source. On the other hand, we used the Harman's unrotated one-factor solution procedure as suggested by Podsakoff et al. (2003). Based on the analysis, a fourfactor solution with eigenvalues all greater than one emerged as the outcome of the Harman's unrotated one-factor solution. The highest variance recorded by the most prominent factor, that is, the first factor, was 37.3 percent. Therefore, we can conclude that $\mathrm{CMB}$ does not pose a serious problem to the current study. Furthermore, we used the Cronbach's alpha coefficient for the purpose of assessing the reliability of the survey instrument, more specifically, the research constructs. The Cronbach's alpha score for the combined research constructs is 0.83 , and this value exceeds the baseline value of 0.7 (Nunnally, 1978). Besides, two items with very low inter-item correlation coefficients were omitted in the final data analysis. In sum, the Cronbach's alpha values for the individual constructs ranged from 0.74 to 0.97 . The unidimensionality of the research constructs was further tested by using principal component analysis (PCA) with 
a varimax orthogonal rotation technique. All the items for each of the constructs were extracted based on the criterion of eigenvalues greater than one. In all, all the factor loadings exceeded 0.5 , thus indicating that at least 50 percent of the constructs' variability was captured by the measurement items used in the study. The results to a large extent confirm the internal consistency and, importantly, the unidimensionality of the research constructs. In this study, we conducted independent PCA for all our constructs (e.g., see Park and Gretzel, 2010). Please refer to Table 4 for more information on the psychometric properties of the scale.

\subsection{Empirical Findings and Discussion}

As shown in Table 5, the overall research model $(\Delta F)$ is statistically significant at $p<0.01$. Prior to entering the independent and moderating variables sequentially into the model, we standardize these variables in order to avoid the problem of multicollinearity (Dunlap and Kemery, 1987). Findings from the collinearity statistics show that the highest variance inflation factor (VIF) value is 3.61 (see Appendix A), thus confirming that multicollinearity is not an issue in the model. Further findings show that the three sub-models in the ANOVA table (see Appendix B) are statistically significant at $p<0.01$. Importantly, the model as a whole is able to capture about 57 percent of the variability of the outcome variable, that is, customer relationship performance.

Therefore, we can deduce that the empirical model as a whole is valid. Although our hypotheses appear to be stated in the form of a one-tailed directional test, we used a two-tailed test to test the statistical hypotheses since there is little or no empirical evidence in the context of small service firms (cf. Cho and Abe, 2013). 


\begin{tabular}{|c|c|c|c|c|c|c|c|c|c|c|c|c|}
\hline 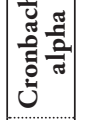 & 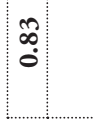 & & & $\stackrel{\circ}{\circ}$ & & & & $\hat{o}$ & & & & \\
\hline 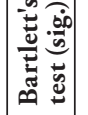 & 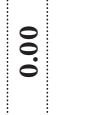 & & & $\because$ & & & & $\begin{array}{l}8 \\
0 \\
0\end{array}$ & & & & \\
\hline 童 & : & & & $\stackrel{2}{3}$ & & & & $\stackrel{\infty}{\infty}:$ & & & & \\
\hline 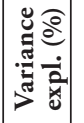 & : & & & శ్7 & & & & $\hat{\hat{\infty}}$ & & & & \\
\hline 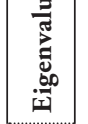 & पे & & & $\stackrel{2}{3}$ & & & & f & & & & \\
\hline 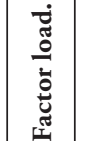 & $\hat{\delta}$ & 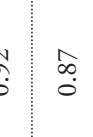 & $\hat{o}$ & : & $\begin{array}{l}\infty \\
\stackrel{0}{0}\end{array}$ & $\begin{array}{ll}\infty \\
\stackrel{0}{0}\end{array}$ & ' & & م̂ & $\stackrel{\circ}{\circ}$ & $\hat{a}$ & ồ \\
\hline के & $\because:$ & $\begin{array}{l}\infty \\
\vdots \\
\infty \\
\infty \\
0\end{array}$ & $\infty$ & î & $: \overbrace{0}^{0}$ & 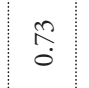 & $\stackrel{8}{0}$ & 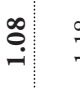 & $\stackrel{\infty}{\leftrightarrows}$ & $\stackrel{\cong}{=}$ & $\stackrel{9}{\leftrightarrows}$ & $\stackrel{ \pm}{=}$ \\
\hline 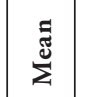 & î. $\vec{i}$ & $\vec{i}$ & $\stackrel{\infty}{\stackrel{\infty}{i}}$ & $\stackrel{\infty}{i} \underset{i}{\infty}$ & $:$ î̀ & în & $\vec{i}$ & $\mid \begin{array}{l}\infty \\
\dot{d}\end{array}$ & $\begin{array}{l}\stackrel{\infty}{d} \\
\stackrel{i}{i}\end{array}$ & $\begin{array}{l}\stackrel{\infty}{\text { iे }} \\
\text { in }\end{array}$ & $\underset{\substack{i \\
i}}{\infty}$ & $\begin{array}{c}\infty \\
\infty \\
\infty\end{array}$ \\
\hline 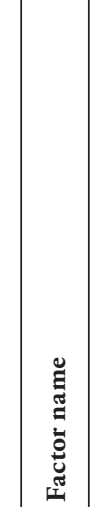 & 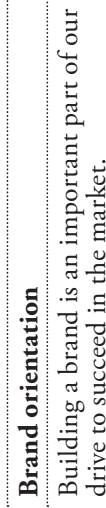 & 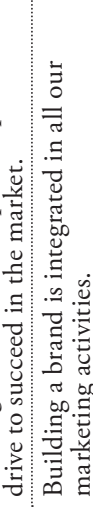 & 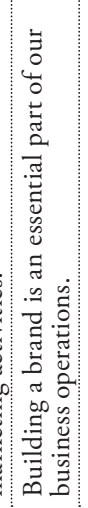 & 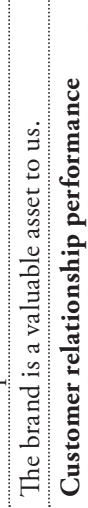 & 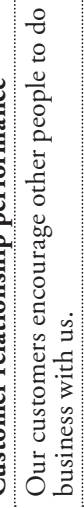 & 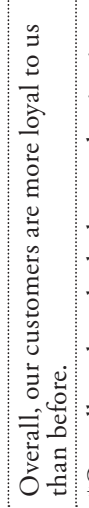 & 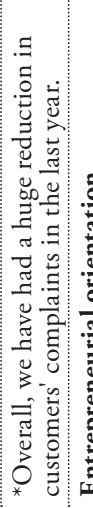 & 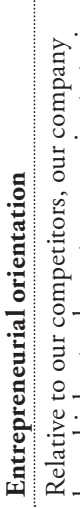 & , & 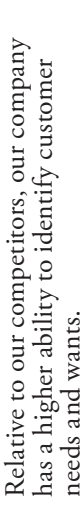 & 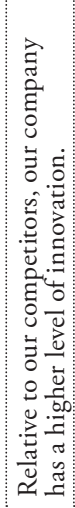 & 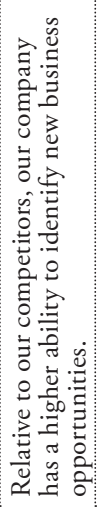 \\
\hline
\end{tabular}


In this study, we do not dwell much on the various typologies (e.g., homologizer, quasi-moderator, pure moderator, etc.) associated with a moderated regression analysis (cf. Sharma, Durand and Gur-arie, 1981). In terms of the practical significance of the overall research model, that is, using the Cohen's effect size, $f^{2}$ equals 0.33 ; this result indicates a relatively high effect size and it particularly provides further validity of the research model. For the sake of model parsimony, we focused our attention on the significance of the direct effects and interaction effects in models 2 and 3, respectively (see Table 5).

In order to derive H1, we made use of model 2 in the research model (see Table 5). The findings show that brand orientation is positively related to customer relationship performance $(P<0.001)$, thus providing empirical support for H1. Therefore, our finding is akin to the finding of O'Cass and Ngo (2011) who empirically demonstrated in a study that was conducted among Australian service firms (with a large proportion of the firms being SMEs) that a service firm's brand orientation positively influences customer satisfaction. In a related study that was conducted in the context of small firms in two EU countries, Finland and Hungary, Laukinnen et al. (2013) found that brand orientation is a significant predictor of brand performance, especially in terms of strong customer-brand loyalty and acquisition of new customers in a SME setting.

Further findings reveal that the relationship between brand orientation and customer relationship performance is reinforced under high entrepreneurial orientation $(p<0.01)$, thus lending support for H2. This new finding responds to the call by Baumgarth (2010). As suggested by Aiken and West (1991), we conducted a simple slope analysis using an Interaction tool (Soper, 2012). The interaction plot is as shown in Figure 2. It shows that brand orientation significantly impacts customer relationship only at a higher level of entrepreneurial orientation, thus providing additional support for $\mathrm{H} 2$.

On the other hand, we do not have sufficient empirical evidence for $\mathrm{H} 3$; our result suggests that perceived competitive intensity does not significantly moderate the 
relationship between brand orientation and customer relationship performance (see Table 5). Based on this inconclusive evidence for $\mathrm{H} 3$, we do not elaborate further on its interaction plot.

However, further insights from the moderated regression analysis show that perceived competitive intensity is an independent predictor of customer relationship performance $(P<0.01)$, though this particular finding was not part of the initial hypothesis. Nonetheless, since it is an important finding from a post-hoc analysis, we considered it useful to report this new finding. Therefore, it could be inferred from our findings that as a result of higher perception of competitive intensity, small service firms are able to up the ante towards building strong and symbiotic relationships with their clients. This finding further highlights the importance of healthy rivalry among firms since it does not only benefit customers, but also the society at large, especially profit-seeking firms. This particular finding relates to the findings of Wieseke et al. (2012) who demonstrate using their baseline model that competitive intensity may positively affect customer satisfaction with sales interaction in the context of sales representatives. This obviously leads us to conclude that a greater perception of competitive intensity is a driver of customer relationship performance among small service firms.

Additionally, a post-hoc power estimate of this analysis, implemented using an online tool (Soper, 2015), equally confirmed the statistical power of the sample size to be more than adequate for the current study since the obtained estimate exceeded the suggested 80 percent statistical power, with an alpha level of 0.05 and 0.15 as the medium effect size (cf. Borges, 2013; Carbonell, RodriguezEscudero and Pujari, 2009; Onwuegbuzie and Leech, 2004). This further provides ample evidence for the adequacy of the sample size as well as additional confirmation of the research findings. 
Table 5: Moderated Regression Analysis (Customer Relationship Performance as Outcome Variable)

\begin{tabular}{|c|c|c|c|c|c|c|}
\hline \multirow{2}{*}{ Predictors } & \multicolumn{2}{|c|}{ Model I } & \multicolumn{2}{|c|}{ Model II } & \multicolumn{2}{|c|}{ Model III } \\
\hline & $\beta$ & t-value & $\beta$ & t-value & $\beta$ & t-value \\
\hline Constant & 2.58 & $39.20^{* * *}$ & 2.58 & $48.23^{* * *}$ & 2.57 & $51.99^{* * *}$ \\
\hline $\mathrm{BO}$ & 0.25 & $3.83^{* * *}$ & 0.18 & $3.21^{* *}$ & 0.18 & $3.35^{* * *}$ \\
\hline $\mathrm{EO}$ & & & 0.13 & $2.27^{*}$ & 0.11 & 1.83 \\
\hline PCI & & & 0.35 & $6.13^{* * *}$ & 0.19 & $3.18^{* *}$ \\
\hline $\mathrm{BO} * \mathrm{EO}$ & & & & & 0.21 & $2.86^{* *}$ \\
\hline $\mathrm{BO} * \mathrm{PCI}$ & & & & & 0.06 & 1.06 \\
\hline$R^{2}$ & \multicolumn{2}{|c|}{0.12} & \multicolumn{2}{|c|}{0.43} & \multicolumn{2}{|c|}{0.57} \\
\hline$\Delta R^{2}$ & \multicolumn{2}{|c|}{0.12} & \multicolumn{2}{|c|}{0.31} & \multicolumn{2}{|c|}{0.14} \\
\hline Adj. $R^{2}$ & \multicolumn{2}{|c|}{0.12} & \multicolumn{2}{|c|}{0.42} & \multicolumn{2}{|c|}{0.55} \\
\hline$\Delta F$ & \multicolumn{2}{|c|}{$14.65^{* * *}$} & \multicolumn{2}{|c|}{$27.48^{* * *}$} & \multicolumn{2}{|c|}{$15.89^{* * *}$} \\
\hline \multicolumn{7}{|c|}{ Cohen's $f^{2}($ effect size $)=0.33$} \\
\hline
\end{tabular}

Notes: Unstandardized regression coefficients are reported in the table; ${ }^{* * *} \mathrm{p}<0.001,{ }^{* *} \mathrm{p}<0.01,{ }^{*} \mathrm{p}<0.05$ (two-tailed test).

Source: Authors' computations extracted from SPSS.

Figure 2: Two-Way Interaction Plot: The Moderating Effect of Entrepreneurial Orientation

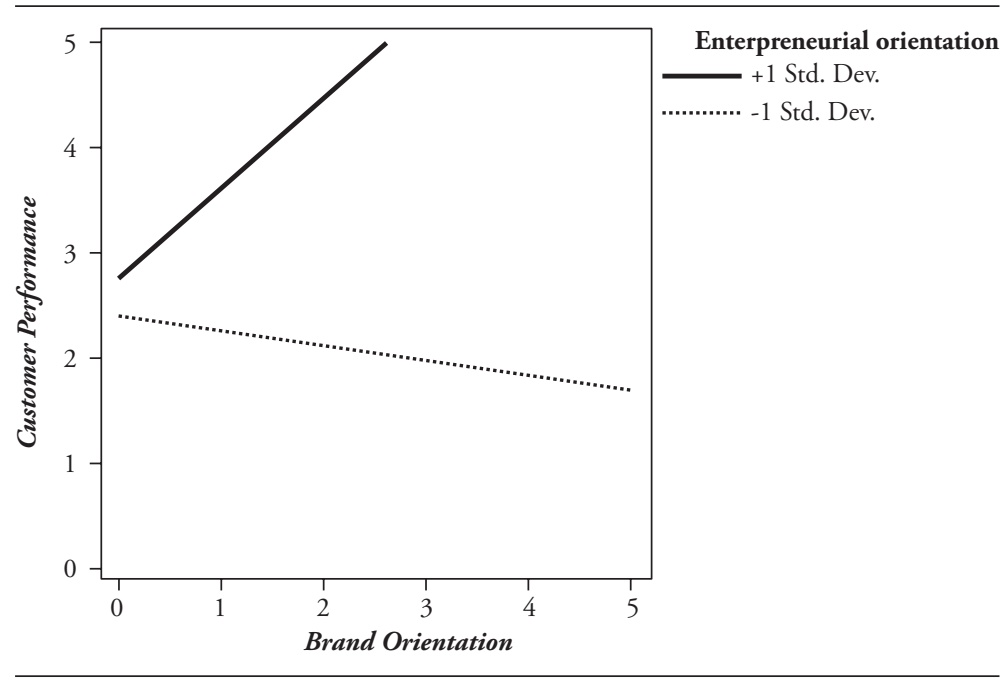

Source: Authors' computations extracted from Soper's Interaction software. 


\section{Research Implications, Limitations, and Future Study}

Based upon the findings, the study implies that small service firms that are more brand-oriented than their counterparts in the service industry are more likely to have more satisfied cum brand-loyal customers.

Just as our empirical findings have shown that there is a direct link between brand orientation and customer relationship performance in the context of small service firms, on the other hand, it is important to point out (and as demonstrated in the research model) that small service firms that have a higher tendency of engaging in strategic planning activities, innovative practices and with the capacity to identify new business opportunities stand a better chance of using their branding strategy to cultivate an enriching relationship with their clients.

In sum, the higher the entrepreneurial orientation of a small service firm, the more it will amplify the relationship between brand orientation and customer relationship performance in the marketplace. Existing literature has always pointed to the active and invaluable role that the small business entrepreneurs play in their organizations since they are the key decision-makers of their establishments (Osakwe, Chovancová and Agu, 2015). Invariably, this further implies that small service firms that expect to benefit more from investing in their firm and/or service branding as bait for improved customer relationship performance, and in turn economic performance, would have to concurrently improve upon their entrepreneurial capabilities.

On the other hand, we found in this study that competitive intensity is a direct predictor of customer relationship performance, that is, perceived competitive intensity may not necessarily moderate the brand orientation-customer relationship performance link. Although this is an interesting finding, it is not so surprising, for at least one obvious business reason. To put it this way - what could possibly drive firms in the marketplace to improve their relationships with customers? The obvious answer is that as a result of intense rivalry among firms, 
firms are being "forcefully" pushed to adopt competitive business strategies that could improve their customer relationship performance metrics, since it is very obvious that satisfied and/or loyal customers equate to improved revenue for all categories of profit-oriented firms. Undoubtedly, without any form of intense rivalry in an industry or business setting, firms by default are lethargic in building strong and long-lasting relationships with customers since it involves the commitment of both physical and non-physical resources.

Therefore, our findings further imply that small service firms that carry out their business activities in an intensely competitive business environment (for example, the financial services setting) are more likely to seize the opportunity that competition inherently offers in the marketplace in ensuring that their customers are well catered for, which in turn increases brand satisfaction and loyalty. Therefore, this study has shown, to a certain degree, that firms with a higher perception of competitive intensity in their industry are more bound to improve their relationships with existing customers and prospects. Overall, our empirical findings from this preliminary study add marginally to theoretical development in the marketing literature and, importantly, to managerial practice.

For small service firm managers in particular, our study has shown that they should invest in their firm's brand on an ongoing basis if they are to build a sustainable customer relationship performance. Also, it is vital for these CEOs and/or managers to become more entrepreneurially-driven. It is important to point out that brand orientation on its own does not necessarily guarantee a firm's competitive position in the marketplace, but it is at least a source of competitive parity that small service firms could leverage on for the purpose of economic survival in the marketplace (Barney, 2001; Barney and Hesterly, 2006; Urde, 1994). Therefore, brand orientation is one of the key strategic paths that firms, particularly small service firms, could leverage on to bolster their customer relationship performance. 
Similar to most empirical studies, our study is limited in several ways. First, the study employs a non-probabilistic sampling technique, i.e., quota sampling. The reason for this is because we could not obtain a sampling frame of our target population due to the typical problem that is associated with carrying out primary research in most developing economies. Another limitation of the present study is that we have used cross-sectional data, thus our findings do not take into account the various dynamics that might have occurred as a result of variations in time periods. Importantly, the research setting was a developing market economy and as such our findings may not be applicable to small service firms in mature market economies and even in dissimilar cross-cultures. Readers should equally take into account that the firms that participated in our study are all from a related industry, the financial industry.

On the other hand, we firmly believe that these limitations could further academic discourse on the relationship between branding and customer relationship performance, especially in the context of micro, small and medium-sized firms. Future studies could expand on the conceptual model by incorporating important strategic variables such as technological turbulence, brand artefacts, managerial ties (social networks), customer feedback, and access to financial capital into the model. It would also be interesting to extend the existing model into non-service sectors, especially small manufacturing and/or agro-allied firms. Likewise, to further the generalizability of the research findings, it would be interesting to replicate this study in a cross-cultural context involving at least two countries from a different continent.

\section{Concluding Thoughts}

To sum up, the main aim of this paper was to empirically investigate the likely impact(s) that the moderating effects of entrepreneurial orientation together with perceived competitive intensity might have on the relationship between brand orientation and customer relationship performance of small service firms as well 
as the direct impact of brand orientation on customer relationship performance. Our results have clearly demonstrated that entrepreneurial orientation reinforces the empirical link between brand orientation and customer relationship performance. We have equally established that there is a direct link between brand orientation and customer relationship performance in a small service firm setting.

Further insights from the research model reveal that a firm's perception of competitive intensity might not significantly moderate the brand orientationcustomer relationship performance link, but that competitive intensity is more likely to be an independent predictor of customer relationship performance. This particular finding, though not part of our initial hypothesis, shows that a competitive business environment drives firms to build and maintain good customer-brand relationships, which in turn is expected to improve a firm's financial bottom-line. Importantly, we expect that the research findings will add to our understanding of how branding influences customer satisfaction as well as customer-brand loyalty, that is, customer relationship performance, in the context of small service firms.

In terms of the practical significance of the overall research model, the effect size is fairly large (Cohen's $f^{2}=0.33$ ), thus further confirming the research findings. By and large, caution should be taken when generalizing the outcomes of this study in dissimilar service sectors given that our findings are still preliminary in nature and this is the first in a series of empirical investigations focused on quantitatively measuring the likely impact(s) that brand orientation may have on small firms' marketing performance (in this instance, customer relationship performance).

\section{Acknowledgements}

The article received support from the Internal Grant Agency of FaME TBU in Zlin (IGA/FaME/2015/025; IGA/FaME/2015/039). 


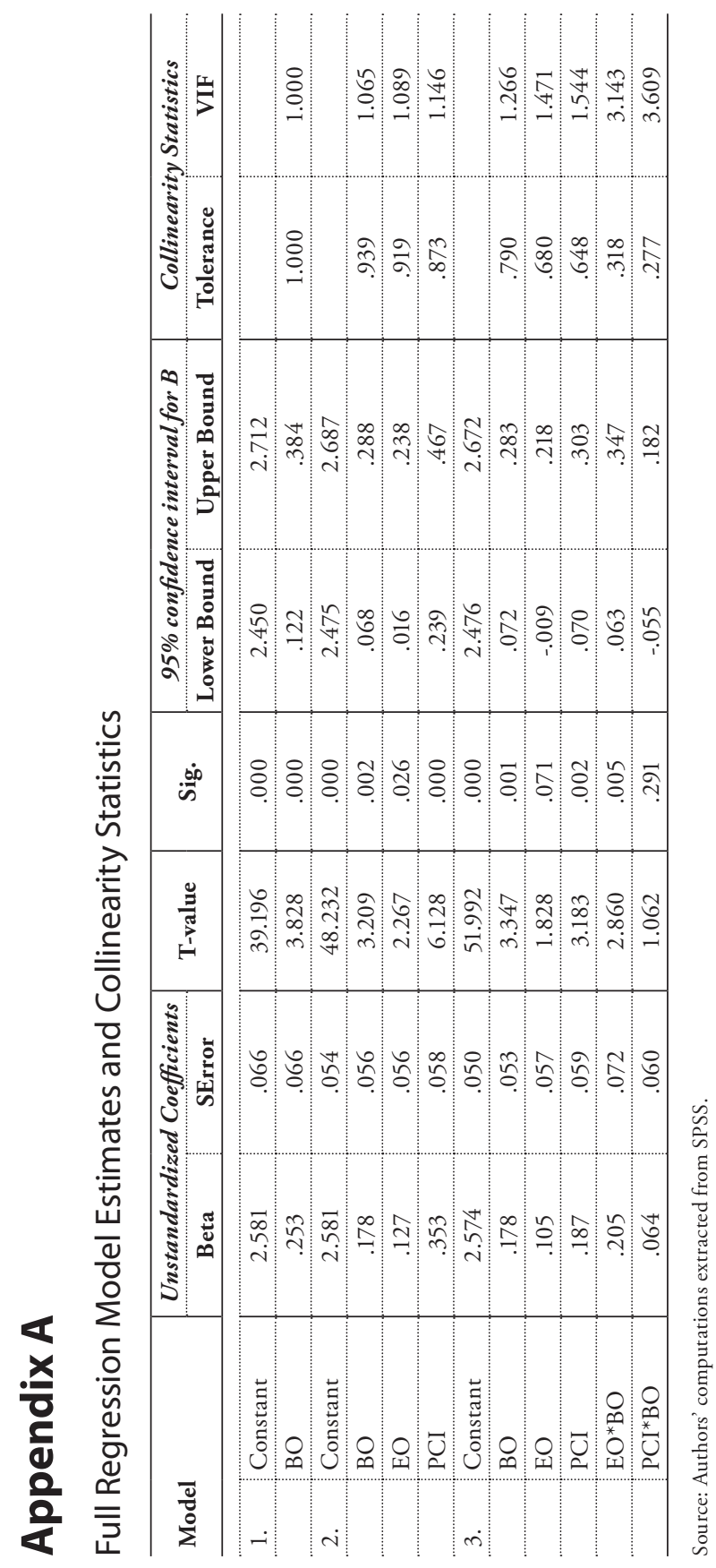




\section{Appendix B}

\section{ANOVA Table of Regression Model}

\begin{tabular}{|c|c|c|c|c|c|c|}
\hline \multicolumn{2}{|c|}{ Model } & $\begin{array}{l}\text { Sum of } \\
\text { Squares }\end{array}$ & df & $\begin{array}{l}\text { Mean } \\
\text { Square }\end{array}$ & $\mathbf{F}$ & Sig. \\
\hline \multirow[t]{3}{*}{1.} & Regression & 6.670 & 1 & 6.670 & 14.650 & .000 \\
\hline & Residual & 48.892 & 103 & .455 & & \\
\hline & Total & 53.562 & 104 & & & \\
\hline \multirow[t]{3}{*}{2.} & Regression & 23.195 & 3 & 7.732 & 25.715 & .000 \\
\hline & Residual & 30.367 & 101 & .301 & & \\
\hline & Total & & 104 & & & \\
\hline \multirow[t]{3}{*}{3.} & Regression & 30.573 & 5 & 6.115 & 26.333 & .000 \\
\hline & Residual & 22.989 & 99 & .232 & & \\
\hline & Total & 53.562 & 104 & & & \\
\hline
\end{tabular}

Source: Authors' computations extracted from SPSS.

\section{Literature}

Aaker, David A., 1996a, Building Strong Brands, New York, NY: The Free Press.

Aaker, David A., 1996b, "Measuring Brand Equity across Products and Markets", California Management Review, 38(3), pp. 102-120. http://dx.doi. org/10.2307/41165845

Abimbola, Temi and Christine Vallaster, 2007, "Brand, Organisational Identity and Reputation in SMEs: An Overview", Qualitative Market Research: An International Journal, 10(4), pp. 341-348. http://dx.doi. org/10.1108/13522750710819685

Aiken, Leona S. and Stephen G. West, 1991, Multiple Regression: Testing and Interpreting Interactions, Thousand Oaks, CA: Sage.

Arnold, Todd J., Eric (Er) Fang and Robert W. Palmatier, 2011, "The Effects of Customer Acquisition and Retention Orientations on a Firm's Radical and Incremental Innovation Performance", Journal of the Academy of Marketing Science, 39(2), pp. 234-251. http://dx.doi.org/10.1007/s11747-010-0203-8 
Barney, Jay B., 2001, "Is the Resource-Based 'View' a Useful Perspective for Strategic Management Research? Yes", Academy of Management Review, 26(1), pp. 41-56.

Barney, Jay B. and William S. Hesterly, 2006, Strategic Management and Competitive Advantage: Concepts and Cases, Upper Saddle River, NJ: Pearson/ Prentice Hall.

Baumgarth, Carsten, 2010, "Living the Brand': Brand Orientation in the Business-to-Business Sector", European Journal of Marketing, 44(5), pp. 653-671. http://dx.doi.org/10.1108/03090561011032315

Bergkvist, Lars I., 2004, "Does Confidence Moderate or Predict Brand Attitude and Purchase Intention?" in Jim Wiley, ed., Proceedings of the Australian and New Zealand Marketing Academy Conference, pp. 1-6, Wellington: Australian and New Zealand Marketing Academy, http://ro.uow.edu.au/cgi/viewcontent.cg i?article=3938\&context=commpapers (accessed February 19, 2015).

Berthon, Pierre, Michael T. Ewing and Julie Napoli, 2008, "Brand Management in Small to Medium-Sized Enterprises", Journal of Small Business Management, 46(1), pp. 27-45. http://dx.doi.org/10.1111/j.1540-627X.2007.00229.x

Borges, Renata, 2013, "Are Public Officials Really Less Satisfied than Private Sector Workers? A Comparative Study in Brazil", Rev. Adm. Pública - Rio de Janeiro, 47(6), pp. 1477-496. http://dx.doi.org/10.1590/S0034-76122013000600007

Carbonell, Pilar, Ana I. Rodriguez-Escudero and Devashish Pujari, 2009, "Customer Involvement in New Service Development: An Examination of Antecedents and Outcomes", Journal of Product Innovation Management, 26(5), pp. 536-550. http://dx.doi.org/10.1111/j.1540-5885.2009.00679.x

Cho, Hyun-Chul and Shuzo Abe, 2013, "Is Two-Tailed Testing for Directional Research Hypotheses Tests Legitimate?", Journal of Business Research, 66(9), pp. 1261-1266. http://dx.doi.org/10.1016/j.jbusres.2012.02.023 
Dunlap, William P. and Edward R. Kemery, 1987, "Failure to Detect Moderating Effects: Is Multicollinearity the Problem?”, Pyschological Bulletin, 102(3), pp. 418-420, cited in Bergkvist (2004: 2).

Džafić, Zijad, Sejfudin Zahirović, Jasmina Okičić and Amra Kožarić, 2011, "Internal and External Obstacles to the Development of SMEs in Bosnia and Herzegovina", Croatian Economic Survey, 13(1), pp. 143-171.

Green, Samuel B., 1991, "How Many Subjects Does It Take To Do a Regression Analysis?", Multivariate Behavioral Research, 26(3), pp. 499-510. http://dx.doi. org/10.1207/s15327906mbr2603_7

Hankinson, Philippa, 2002, "The Impact of Brand Orientation on Managerial Practice: A Quantitative Study of the UK's Top 500 Fundraising Managers", International Journal of Nonprofit and Voluntary Sector Marketing, 7(1), pp. 3044. http://dx.doi.org/10.1002/nvsm.165

International Labour Organization, 2006, "Poverty Reduction through Small Enterprises: Emerging Consensus, Unresolved Issues and ILO Activities", SEED Working Paper, No. 75, http://www.oit.org/wcmsp5/groups/public/---ed_emp/--emp_ent/documents/publication/wcms_093981.pdf (accessed July 30, 2014).

Kapferer, Jean-Noël, 2008, The New Strategic Brand Management: Creating and Sustaining Brand Equity Long Term (4th ed.), London: Kogan Page.

Laukkanen, Tommi, Gábor Nagy, Saku Hirvonen, Helen Reijonen and Mika Pasanen, 2013, "The Effect of Strategic Orientations on Business Performance in SMEs: A Multigroup Analysis Comparing Hungary and Finland", International Marketing Review, 30(6), pp. 510-535. http://dx.doi.org/10.1108/IMR-09-20110230

Lumpkin, G. T. and Gregory G. Dess, 2001, "Linking Two Dimensions of Entrepreneurial Orientation to Firm Performance: The Moderating Role of Environment and Industry Life Cycle", Journal of Business Venturing, 16(5), pp. 429-451. http://dx.doi.org/10.1016/S0883-9026(00)00048-3 
Mead, Donald C. and Carl Liedholm, 1998, "The Dynamics of Micro and Small Enterprises in Developing Countries", World Development, 26(1), pp. 61-74. http://dx.doi.org/10.1016/S0305-750X(97)10010-9

Merrilees, Bill, Sharyn Rundle-Thiele and Ashley Lye, 2011, "Marketing Capabilities: Antecedents and Implications for B2B SME Performance", Industrial Marketing Management, 40(3), pp. 368-375. http://dx.doi.org/10.1016/j. indmarman.2010.08.005

Napoli, Julie, Michael T. Ewing and Pierre Berthon, 2005, "Brand Matters: An Examination of Small-to-Medium Sized Enterprises", paper presented at the conference "Australian and New Zealand Marketing Academy Conference" organized by ANZMAC, Perth, December 5, http://www.anzmac.org/ conference_archive/2005/cd-site/pdfs/2-Branding/2-Napoli.pdf (accessed January 18, 2015).

Nunnally, Jum C., 1978, Psychometric Theory (2nd ed.), New York, NY: McGrawHill.

O'Cass, Aron and Liem Viet Ngo, 2011, "Achieving Customer Satisfaction in Services Firms via Branding Capability and Customer Empowerment", Journal of Services Marketing, 25(7), pp. 489-496. http://dx.doi. org/10.1108/08876041111173615

O'Cass, Aron and Jay Weerawardena, 2010, “The Effects of Perceived Industry Competitive Intensity and Marketing-Related Capabilities: Drivers of Superior Brand Performance", Industrial Marketing Management, 39(4), pp. 571-581. http://dx.doi.org/10.1016/j.indmarman.2009.04.002

Onwuegbuzie, Anthony J. and Nancy L. Leech, 2004, "Post Hoc Power: A Concept Whose Time Has Come”, Understanding Statistics, 3(4), pp. 201-230. http://dx.doi.org/10.1207/s15328031us0304_1 
Osakwe, Christian Nedu, Miloslava Chovancová and Monica Agu, 2015, "Can Micro-Enterprises Leverage on the Adoption of Corporate Website to Bolster Their Brand Visibility? Examining Salient Adoption Issues in a Developing Country Context", Information Development (Forthcoming). http://dx.doi. org/10.1177/0266666915573551

Park, Sang I. L. and Mi Jeong Kim, 2013, "Does Brand Orientation Matter? An Empirical Study of Korean SMEs”, Asia Marketing Journal, 14(4), pp. 117-142.

Park, Young A. and Ulrike Gretzel, 2010, "Influence of Consumers' Online Decision-Making Style on Comparison Shopping Proneness and Perceived Usefulness of Comparison Shopping Tools", Journal of Electronic Commerce Research, 11(4), pp. 342-354.

Podsakoff, Philip M., Scott B. MacKenzie, Nathan P. Podsakoff and Jeong Yeong Lee, 2003, "The Mismeasure of Man(agement) and Its Implications for Leadership Research", The Leadership Quarterly, 14(6), pp. 615-656. http:// dx.doi.org/10.1016/j.leaqua.2003.08.002

Schmidt, Holger J. and Carsten Baumgarth, 2014, "Introducing a Conceptual Model of Brand Orientation within the Context of Social Entrepreneurial Businesses", International Journal on Strategic Innovative Marketing, 1(1), pp. $37-$ 50. http://dx.doi.org/10.15556/IJSIM.01.01.004

Sharma, Subhash, Richard M. Durand and Oded Gur-arie, 1981, "Identification and Analysis of Moderator Variables" Journal of Marketing Research, 18(3), pp. 291-300. http://dx.doi.org/10.2307/3150970

Soper, Daniel S., 2012, Interaction version 1.7.2211, http://www.danielsoper. com/Interaction (accessed January 15, 2015).

Soper, Daniel, 2015, Statistics Calculators version 3.0, http://www.danielsoper. com/statcalc3/default.aspx (accessed February 19, 2015).

Urde, Mats, 1994, "Brand Orientation - A Strategy for Survival", Journal of Consumer Marketing, 11(3), pp. 18-32. http://dx.doi.org/10.1108/ 07363769410065445 
Urde, Mats, 1999, "Brand Orientation: A Mindset for Building Brand into Strategic Resources", Journal of Marketing Management, 15(1-3), pp. 117-133. http://dx.doi.org/10.1362/026725799784870504

Urde, Mats, Carsten Baumgarth and Bill Merrilees, 2013, "Brand Orientation and Market Orientation - From Alternatives to Synergy", Journal of Business Research, 66(1), pp. 13-20. http://dx.doi.org/10.1016/j.jbusres.2011.07.018

Van Gelder, Sicco, 2003, Global Brand Strategy: Unlocking Brand Potential Across Countries, Cultures \& Markets, London: Kogan Page.

Wallace, Elaine, Leslie de Chernatony and Isabel Buil, 2011, "How Leadership and Commitment Influence Bank Employees' Adoption of Their Bank's Values", Journal of Business Ethics, 101(3), pp. 397-414. http://dx.doi.org/10.1007/s10551010-0728-2

Wieseke, Jan, Florian Kraus, Michael Ahearne and Sven Mikolon, 2012, "Multiple Identification Foci and Their Countervailing Effects on Salespeople's Negative Headquarters Stereotypes", Journal of Marketing, 76(3), pp. 1-20. http:// dx.doi.org/10.1509/jm.10.0444

Wilson VanVoorhis, Carmen R. and Betsy L. Morgan, 2007, "Understanding Power and Rules of Thumb for Determining Sample Sizes", Tutorials in Quantitative Methods for Psychology, 3(2), pp. 43-50.

Wong, Ho Yin and Bill Merrilees, 2005, "A Brand Orientation Typology for SMEs: A Case Research Approach", Journal of Product \& Brand Management, 14(3), pp. 155-162. http://dx.doi.org/10.1108/10610420510601021

Wong, Ho Yin and Bill Merrilees, 2008, "The Performance Benefits of Being Brand Oriented", Journal of Product \& Brand Management, 17(6), pp. 372-383. http://dx.doi.org/10.1108/10610420810904112

Wu, Fang, Vijay Mahajan and Sridhar Balasubramanian, 2003, "An Analysis of E-Business Adoption and Its Impact on Business Performance", Journal of the Academy of Marketing Science, 31(4), pp. 425-447. http://dx.doi. org/10.1177/0092070303255379 